\title{
Electrical, thermal and infrared studies of cerium(III) orthovanadate
}

\author{
N SURESH RAO and O G PALANNA \\ Department of Chemistry, St. Philomena College, Puttur 574 202, India
}

MS received 13 March 1995; revised 26 June 1995

\begin{abstract}
Cerium(III) orthovanadate with a small deviation from stoichiometric composition is a $p$-type semiconductor between 30 and $800^{\circ} \mathrm{C}$. The electrical conduction in cerium(III) orthovanadate is due to thermally activated hopping of holes on equivalent $\mathrm{Ce}^{3+}-\mathrm{Ce}^{4+}$ lattice sites. The DTA result of $\mathrm{CeVO}_{4}$ indicated a possible phase transition at about $70^{\circ} \mathrm{C}$. The IR spectrum of the sample showed bands at 865 and $810 \mathrm{~cm}^{-1}$, typical of $\mathrm{VO}_{4}$ group of orthovanadates.
\end{abstract}

Keywords. Semiconductor; nonstoichiometric composition; phase transition.

\section{Introduction}

The phase studies of the binary $\mathrm{Ce}_{2} \mathrm{O}_{3}-\mathrm{V}_{2} \mathrm{O}_{5}$ system containing trivalent state, $\mathrm{Ce}^{3+}$ $(1 \cdot 17 \AA)$ in the lattice indicated the formation of phase of composition, $\mathrm{CeVO}_{4}$. The cerium(III) orthovanadate crystallized in the tetragonal zircon $\left(\mathrm{ZrSiO}_{4}\right)$ type crystal structure (Schwartz 1963; Wycoff 1965; Yashimura and Sata 1969) and was isostructural with the tetragonal modification of $\mathrm{LaVO}_{4}$ (Escobar and Baran 1978) containing lanthanum in trivalent oxidation state $(1.07 \AA)$. The IR bands of the lanthanide orthovanadates were reported by Ayamonino and Baran (1971) and Muller et al(1976). In this communication, we report results of electrical, thermal and IR studies of the orthovanadate of the trivalent state rare earth, $\mathrm{Ce}^{3+}$.

\section{Experimental}

Cerium(III) orthovanadate was obtained by heating a mixture of $\mathrm{Ce}_{2} \mathrm{O}_{3}$ and $\mathrm{V}_{2} \mathrm{O}_{5}$ (both $\mathrm{AR}$ grade) in $1: 1$ molar ratio at $700^{\circ} \mathrm{C}$ for $5-6$ days adopting the conventional solid state ceramic technique. The dc electrical conductivity $(\sigma)$ of the sample was measured using a fabricated unit adopting the conventional two-probe technique and the Seebeck coefficient $(\alpha)$ by the integral method between 30 and $800^{\circ} \mathrm{C}$. The sample (18 $\mathrm{mm}$ diam and $2 \mathrm{~mm}$ thickness) was in the form of sintered pellet of high density. The differential thermal analysis (DTA) of the sample was carried out in a fabricated unit and was recorded using a strip chart recorder of high sensitivity. The following conditions were maintained during the DTA run of the sample: (i) the sample holder, Pt cups, (ii) reference material, anhydrous $\mathrm{Al}_{2} \mathrm{O}_{3}$, (iii) heating rate, $8 \% \mathrm{~min}$ and (iv) atmosphere, static air. The thermogravimetric (TG) and differential thermogravimetric (DTG) analyses of the sample were made using Mettler TA 4000 system. The IR spectrum of the sample was recorded in nujol mull using Perkin Elmer spectrophotometer.

\section{Results and discussion}

The powder XRD of $\mathrm{CeVO}_{4}$ agrees with the one reported earlier (ASTM card File No. 12-757); it has tetragonal zircon $\left(\mathrm{ZrSiO}_{4}\right)$ type (Schwartz 1963; Wycoff 1965) crystal 
structure $(a=7.399 \AA$ and $b=6.496 \AA)$ and is isostructural with a tetragonal $(a=7.49 \AA$ and $b=6.59 \AA)$ modification of $\mathrm{LaVO}_{4}$ (Escobar and Baran 1978). The DTA result of $\mathrm{CeVO}_{4}$ is shown in figure 1 (entire range is not shown). On heating cycle of DTA run, the result indicated an endothermic peak at $70^{\circ} \mathrm{C}$, while an exothermic peak was observed at about $50^{\circ} \mathrm{C}$ during the cooling process of the sample. TG analysis of $\mathrm{CeVO}_{4}$ showed nearly temperature independent weight of the sample over the entire temperature range. The DTA result (figure 1) suggested possible phase transition in $\mathrm{CeVO}_{4}$ at $70^{\circ} \mathrm{C}$, similar to that observed for the tetragonal (Escobar and Baran 1978)

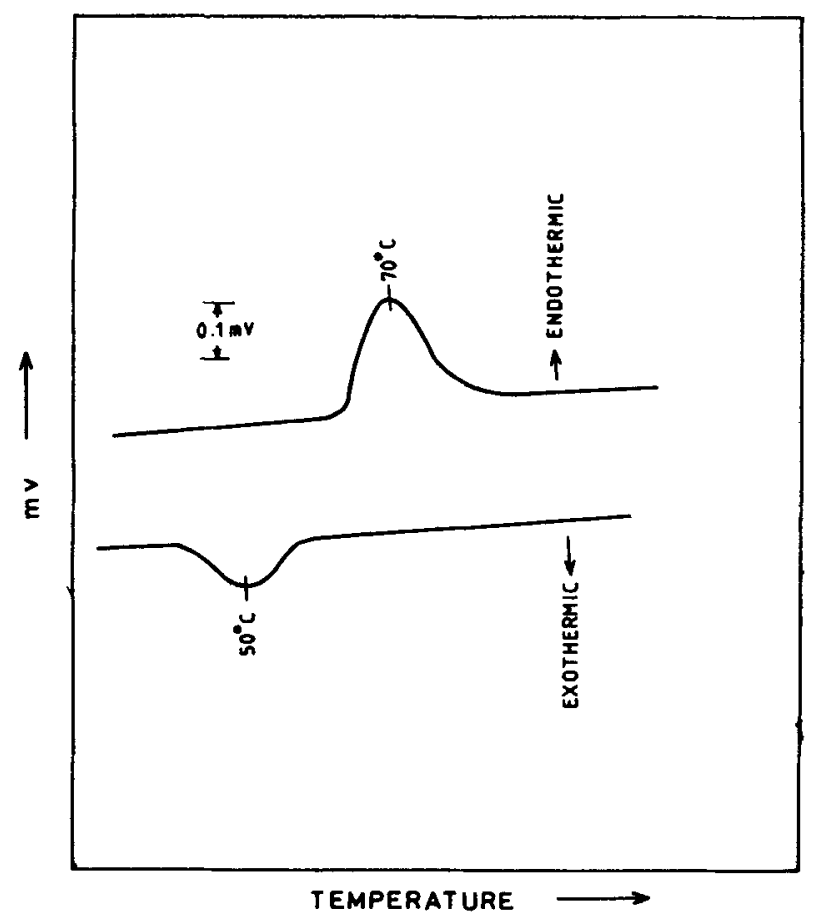

Figure 1. DTA of $\mathrm{CeVO}_{4}$ in static air.

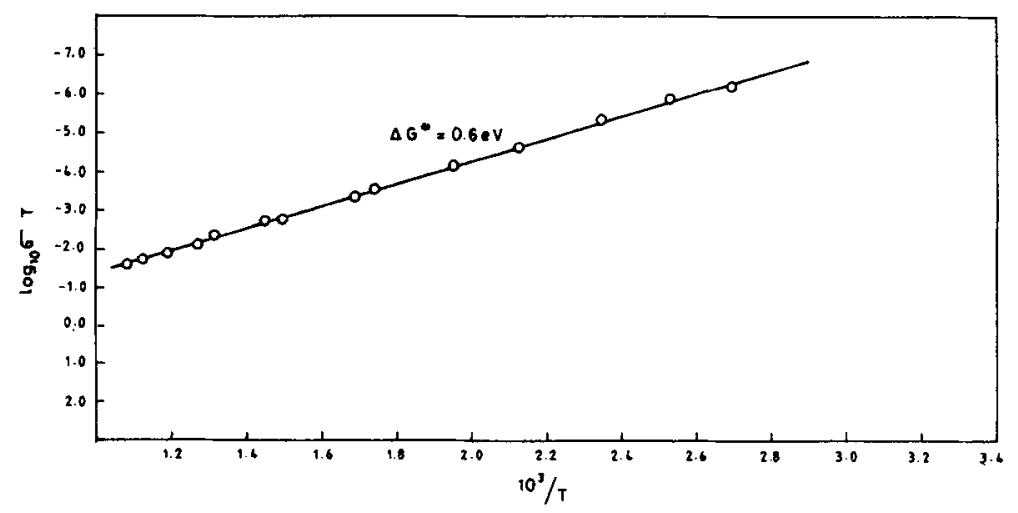

Figure 2. $\log _{10} \sigma T$ vs $10^{3} / T$ for $\mathrm{CeVO}_{4}$. 
and monoclinic phases (Ayamonino and Baran 1971) of $\mathrm{LaVO}_{4}$. However, high temperature XRD is essential to confirm this possibility. The results of the dc electrical conductivity $(\sigma)$ (figure 2 ) indicates that $\sigma$ follows a relationship of the form

$$
\sigma=\frac{\sigma_{0}}{T} \exp -\Delta G^{*} / K T
$$

with an activation energy of $0 \cdot 60 \mathrm{eV}$.

The Seebeck coefficient $(\alpha, \mu \mathrm{V} /$ degree $)$ is, in general,

$$
\alpha=\frac{A}{e T} \pm \log _{10} \frac{N-n}{n},
$$

which for the case of $\mathrm{CeVO}_{4}$, can be described by

$$
\alpha=\frac{A}{e T}+\log _{10} \frac{\mathrm{Ce}^{3+}}{\mathrm{Ce}^{4+}}
$$

where all the terms have their usual significance. The term $A$ represents the kinetic energy (KE) by the charge carriers (holes). The value of $A / e T$ is small for ionic solids. In (2) and (3), $(N-n)=\mathrm{Ce}^{3+}=$ density of sites is available to the mobile holes and $n=\mathrm{Ce}^{4+}$, is the density of mobile holes (cations in higher valence state). Usually, the second term determines the sign of Seebeck coefficient $(\alpha)$.

$\mathrm{CeVO}_{4}$ is an insulator in pure and stoichiometric composition. But, the sample exhibited $p$-type semiconduction between 30 and $800^{\circ} \mathrm{C}$ due to deviation from cation stoichiometry (cation vacant lattice). It is evident from the aforesaid observations that the charge transport in $\mathrm{CeVO}_{4}$ is via thermally activated jump of holes on equivalent $\mathrm{Ce}^{3+}-\mathrm{Ce}^{4+}$ lattice sites. The $p$-type semiconduction observed in cerium orthovanadate lattice could be described as follows: cerium is found to be in trivalent oxidation state in the lattice of $\mathrm{CeVO}_{4}$, while vanadium existed in the highest oxidation state of +5 . The formation of $V^{6+}$ is not energetically favourable in the lattice. Therefore, the possibility for the hole ( $p$-type) conduction in the lattice could be due to the coexistence of a few $\mathrm{Ce}^{4+}$ states in the lattice sites of $\mathrm{Ce}^{3+}$ and the conduction is via thermally activated jumps of holes on equivalent $\mathrm{Ce}^{3+}$ sites. In a close packed array of oxygen atoms, the existence of $\mathrm{Ce}^{4+}$ state ion in the available $\left(\mathrm{Ce}^{3+}\right)$ sites are facilitated by the creation of a few vacant cation sites $\left(\mathrm{Ce}_{\square}^{3+}\right)$, which would give rise to $p$-type semiconduction as given

$$
2 x \mathrm{Ce}^{3+}+3 x \mathrm{O}^{2-}+\frac{x}{2} \mathrm{O}_{2} \rightarrow 2 x \mathrm{Ce}^{4+}+4 x \mathrm{O}^{2-}+\frac{2 x}{3} \mathrm{Ce}_{\square}^{3+}
$$

i.e.

$$
\mathrm{CeVO}_{4}+\frac{x}{2} \mathrm{O}_{2} \rightarrow \mathrm{Ce}_{1-2 x}^{3+} \mathrm{Ce}_{2 x}^{4+} \mathrm{VO}_{4+x}
$$

The absence of signal at $g=1.96$ from ESR spectrum studies of the sample revealed that the $\mathrm{V}^{4+}\left(3 d^{\prime}\right)$ localized sites are not available for conduction in the lattice of $\mathrm{CeVO}_{4}$, unlike the behaviour observed in $\mathrm{FeVO}_{4}$ (Palanna et al 1977; Palanna and Suresh Rao 1995). The $p$-type semiconduction of the sample was due to thermally activated mobility of holes on equivalent $\mathrm{Ce}^{3+}-\mathrm{Ce}^{4+}$ lattice sites.

The Seebeck coefficient $(\alpha)$ was positive and had a value of $+40 \mu \mathrm{V} /{ }^{\circ} \mathrm{C}$ over entire temperature range indicating a constant number of mobile holes $\left(\mathrm{Ce}^{4+}\right)$ in the lattice of 


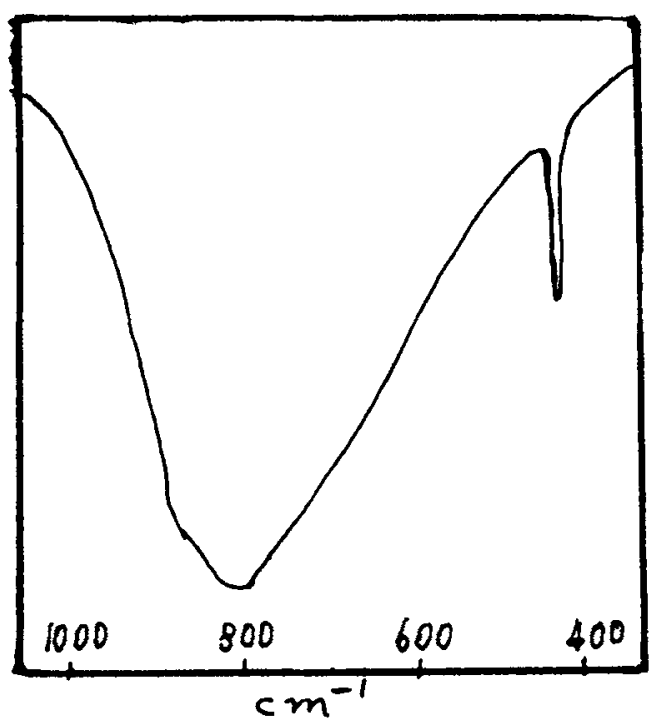

Figure 3. IR spectrum of $\mathrm{CeVO}_{4}$.

$\mathrm{Ce}^{3+}$. The electrical conductance $(\sigma)$ (figure 2 ) and Seebeck coefficient $(\alpha)$ data reported here above $70^{\circ} \mathrm{C}$ refers to high temperature phase of $\mathrm{CeVO}_{4}$. The IR bands characteristic of tetrahedral $\mathrm{VO}_{4}$ group of $\mathrm{CeVO}_{4}$ (Ayamonino and Baran 1971; Muller et al 1976) was observed at 865,810 and $440 \mathrm{~cm}^{-1}$. The $750-900 \mathrm{~cm}^{-1}$ frequency region of spectrum corresponded to the stretching vibrations of the $\mathrm{VO}_{4}$ group of the lattice. Thus, IR bands observed seem to be related to some property of the $\mathrm{V}-\mathrm{O}$ bands of the $\mathrm{VO}_{4}$ group present in zircon $\left(\mathrm{ZrSiO}_{4}\right)$ type crystal structure. These were different from the $\mathrm{VO}_{4}$ group spectral bands observed for $\mathrm{FeVO}_{4}$, which were characteristic of the three distinct distorted tetrahedral groups (Palanna and Suresh Rao 1995). The $\mathrm{CeVO}_{4}$ had tetragonal lattice (Schwartz 1963) with slightly distorted $\mathrm{VO}_{4}$ tetrahedra and the rare earth $\left(\mathrm{Ce}^{3+}\right)$ ions are located between the neighbour tetrahedra (Wycoff 1965). Each $\mathrm{Ce}^{3+}$ ion was dodecahedrally surrounded by eight oxygens. The IR bands observed (figure 3) at 865 and $810 \mathrm{~cm}^{-1}$ for the sample was due to the distorted tetrahdral $\mathrm{VO}_{4}$ groups. For many orthovanadates the $\mathrm{VO}_{4}$ tetrahedral symmetry bands were observed at 870 and $820 \mathrm{~cm}^{-1}$ by Seibert (1954).

\section{Acknowledgements}

The authors sincerely thank the UGC, New Delhi for research grant. They also express their gratitude to Prof. H Sudhakar Rao, Department of Metallurgy, KREC, Surathkal for providing XRD and IR spectrum of the sample.

\section{References}


Muller A, Brown E J and Carter M O 1976 Structure Bond 2681

Palanna O G and Suresh Rao N 1995 Bull. Mater. Sci. 18229

Palanna O G, Shashimohan A L and Biswas A B 1977 Proc. Indian Acad. Sci. A86 455

Schwartz H 1963 Z. Anorg. Allg. Chem. 32344

Seibert H 1954 Z. Anorg. Allg. Chem. 275225

Wycoff R W J 1965 Crystal structure (New York: John-Wiley and Sons) Vol. 3, p. 35

Yashimura M and Sata T 1969 Bull. Chem. Soc. Jap. 423195 